\title{
Effects of mdig on proliferation and apoptosis of lung cancer cells
}

\author{
XIAOHUI XU, LEI CAO, YE ZHANG, HONGJIAN LIAN, ZHIWEI SUN and YUSHANG CUI \\ Department of Thoracic Surgery, Peking Union Medical College Hospital, Beijing 100730, P.R. China
}

Received January 3, 2018; Accepted September 10, 2018

DOI: $10.3892 / 01.2018 .9528$

\begin{abstract}
Expression of mineral dust-induced gene (mdig) in lung cancer NCI-H1650 cells was detected to investigate the effects of mdig on proliferation and apoptosis of NCI-H1650 cells. NCI-H1650 lung cancer cells were cultured in vitro. The expression of mdig in NCI-H1650 cells was lowered using ribonucleic acid interference (RNAi) technique. Reverse transcription-quantitative polymerase chain reaction (RT-qPCR) and western blot analysis were used to detect the effects of mdig small interfering RNA (siRNA) on messenger RNA (mRNA) and the protein expression of mdig in lung cancer NCI-H1650 cells, respectively. The effect of mdig on the proliferation of NCI-H1650 cells was observed through 3-(4,5)-dimethylthiazol (-z-y1)3,5-di-phenyl tetrazolium bromide (MTT) assay, and flow cytometry was used to detect the impact of mdig on cell cycle and apoptosis of NCI-H1650 cells. The influence of mdig on caspase- 3 and poly (ADP-ribose) polymerase 1 (PARP1) proteins in NCI-H1650 cells were investigated via western blot analysis. The results of RT-qPCR and western blot analysis showed that mdig siRNA obviously inhibited the expression of mRNA and protein of mdig in NCI-H1650 cells. Results of the MTT assay showed mdig siRNA could significantly reduce the proliferation ability of NCI-H1650 cells. In addition cell cycle detection showed that mdig siRNA caused NCI-H1650 cell arrest at G1 phase. Apoptosis detection results indicated that mdig siRNA promoted apoptosis of NCI-H1650 cells. Western-blot analysis revealed that mdig siRNA upregulated the expression of cleaved caspase-3 and cleaved PARP1 proteins in NCI-H1650 cells. Mdig is highly expressed in lung cancer NCI-H1650 cells while mdig siRNA can inhibit proliferation of NCI-H1650 cells and accelerate apoptosis. The underlying mechanism may be related to inhibited cell cycle progression and upregulated expression of cleavage proteins (cleaved caspase-3 and cleaved PARP1).
\end{abstract}

Correspondence to: Dr Yushang Cui, Department of Thoracic Surgery, Peking Union Medical College Hospital, 1 Shuaifuyuan, Wangfujing, Dongcheng, Beijing 100730, P.R. China

E-mail: tongyina5@163.com

Key words: mdig, lung cancer, NCI-H1650 cells, proliferation, apoptosis

\section{Introduction}

Lung cancer is one of the most common malignant tumors, with morbidity and mortality ranking the first among those of malignancies, and has become Top 1 among malignant tumors in mankind (1). Studies of World Health Organization have shown that incidence and mortality rates of lung cancer are increasing annually worldwide from the middle of last century to now, and current death roll of patients due to lung cancer has far exceeded the total number of patients who die of breast cancer, prostate cancer and colorectal cancer $(2,3)$.

Survival time of patients has been extended using surgical treatment, chemotherapy, radiotherapy, targeted therapy and other methods, but the 5-year survival rate in lung cancer patients is only $15 \%$ (4). Studies have found that main causes of the high incidence and mortality rates of lung cancer are changes in related genes and signal transduction pathways, such as increase of proto-oncogene expression, decrease of tumor suppressor gene expression and imbalance of intracellular signal transduction pathway, thereby improving tumor cell proliferation, invasion and metastasis abilities, so that tumor cells easily metastasize (5-8). Therefore, studies of tumor-associated genes and their signal transduction pathways in lung cancer cells are useful to identify the mechanisms of occurrence and development of lung cancer, and are of very important clinical significance for finding new drug targets and methods of treatment.

Mineral dust-induced gene (mdig) is a lung cancer-related gene that was first discovered in miners' alveolar macrophages in 2005 (9). Mdig, located on human chromosome 3q11.2, contains 1510 bases in full length. It is able to encode a protein consisting of 465 amino acids and has a molecular weight of $53 \mathrm{kDa}(10)$. A slight expression of mdig was found in normal human tissue cells, but its expression is high in various tumor tissues and cell lines (11-14). A further study showed that mdig can promote tumor cell proliferation and block cell cycle progression (15).

There are few detailed reports on the effects of mdig on proliferation and apoptosis of lung cancer cells and mechanisms of action. Therefore, this study used ribonucleic acid interference (RNAi) technology to silence mdig expression in lung cancer NCI-H1650 cells and then adopted reverse transcription-quantitative polymerase chain reaction (RT-qPCR) and western blot analysis to detect the impact of mdig small interfering RNA (siRNA) on the expression of messenger RNA (mRNA) and protein of mdig in NCI-H1650 cells. The effects of mdig silencing on proliferation, cycle distribution, 
apoptosis and apoptosis-related proteins of NCI-H1650 cells were further studied.

\section{Materials and methods}

Materials. Materials used in the study were: NCI-H1650 human lung cancer cells (Cell Bank of the Chinese Academy of Sciences, Shanghai, China); Dulbecco's modified Eagle's medium (DMEM) and fetal bovine serum (Hyclone, Logan, UT, USA); TRIzol kits and Lipofectamine 2000 (Invitrogen, Carlsbad, CA, USA); bicinchoninic acid (BCA) protein quantification kits and cell lysis buffer (Beyotime Biotechnology, Nantong, China); reverse transcription kits, RT-qPCR kits, primer syntheses, mdig siRNA, and negative control siRNA (N-siRNA) (Takara, Dalian, China); mdig, cleaved caspase-3, cleaved poly (ADP-ribose) polymerase 1 (PARP1), glyceraldehyde-3-phosphate dehydrogenase (GAPDH) primary antibodies, and horseradish peroxidase (HRP)-labeled secondary antibodies (Proteintech Group, Inc., Wuhan, China); cycle detection kits and Annexin V-fluorescein isothiocyanate (FITC) apoptosis detection kits (Beyotime Biotechnology, Nantong, China). The study was approved by the Ethics Committee of Peking Union Medical College Hospital (Beijing, China).

Cell culture and siRNA transfection. NCI-H1650 cells were cultured in DMEM containing $10 \%$ fetal bovine serum at $37^{\circ} \mathrm{C}$ in a $5 \% \mathrm{CO}_{2}$ incubator, the medium was changed every two days, and digestion and passage were performed after cells spread to $80 \%$ of the bottom of the culture bottle. Before transfection, NCI-H1650 cells in logarithmic phase were inoculated into a 6 -well plate at a density of $2 \times 10^{5} /$ well. After $24 \mathrm{~h}$, siRNA transfection was conducted according to instructions of Lipofectamine 2000 for $48 \mathrm{~h}$, with the siRNA sequence shown in Table I. This study included normal control group (control), negative control group (N-siRNA) and experimental group (mdig siRNA).

Effect of mdig siRNA on mRNA expression of mdig in NCI-H1650 cells detected by RT-qPCR. Cells in each group were transfected for $48 \mathrm{~h}$ and then collected to extract total RNA according to recommended methods of TRIzol kits. When the absorbance ratio [the absorbance at 260 and $280 \mathrm{~nm}$ (A260/280)] of samples was between 1.8 and 2.0 , the next reverse transcription reaction was carried out. Then, PCR amplification was performed using the obtained complementary deoxyribonucleic acid (cDNA) as a template according to primer sequence shown in Table II. Specific reaction conditions were as follows: pre-denaturation at $95^{\circ} \mathrm{C}$ for $3 \mathrm{~min}$, then $95^{\circ} \mathrm{C}$ for $15 \mathrm{sec}, 62^{\circ} \mathrm{C}$ for $30 \mathrm{sec}, 72^{\circ} \mathrm{C}$ for $30 \mathrm{sec}$, with 40 cycles in total. GADPH was used as the internal reference. The cycle threshold $(\mathrm{Cq})$ value was output from the instrument, and experimental results were analyzed using the $2^{-\Delta \Delta \mathrm{Cq}}$ method (16).

Impact of mdig siRNA on protein expression of mdig in NCI-H1650 cells via western blot analysis detection. Cells were collected from each group after $48 \mathrm{~h}$ of transfection, added with cell lysis buffer, and centrifuged at $3,000 \mathrm{x}$ g for $10 \mathrm{~min}$ at $4^{\circ} \mathrm{C}$ to extract proteins. The concentration of the extracted protein was
Table I. siRNA sequences.

\begin{tabular}{lcc}
\hline Name & $\begin{array}{c}\text { Sequence } \\
\text { name }\end{array}$ & siRNA sequence \\
\hline mdig & Sense & 5'-UUGUCCGAACGUGUCACGUTT-3' \\
siRNA & Antisense & 5'-ACGUGACACGUUCGGAGAATT-3' \\
N-siRNA & Sense & 5'-GGGCAACGAUUCAGUUUCATT-3' \\
& Antisense & 5'-UGAAACUGAAUCGUUGCCCTT-3'
\end{tabular}

Table II. RT-qPCR primer sequences.

\begin{tabular}{lll}
\hline Gene & $\begin{array}{c}\text { Primer } \\
\text { name }\end{array}$ & Primer sequence \\
\hline mdig & Forward & 5'-GGCAACGATTCAGTTTCACCAA-3' \\
& Reverse & 5'-TGTACACATTCGAGCCAACCAAG-3' \\
GADPH & Forward & 5'-CCTGGTATGACAACGAATTTG-3' \\
& Reverse & 5'-CAGTGAGGGTCTCTCTCTTCC-3' \\
\hline
\end{tabular}

measured by BCA protein concentration kits. Sodium dodecyl sulfate polyacrylamide gel electrophoresis (SDS-PAGE) was carried out, $40 \mu \mathrm{g}$ of protein were loaded on each well, subjected to wet membrane transfer, blocked in 5\% bovine serum albumin (BSA) solution, and incubated at $4^{\circ} \mathrm{C}$ with mdig and GAPDH antibodies (diluted at 1:1,000). After washing the membrane, proteins were added with HRP-labeled secondary antibodies dropwise and incubated at room temperature for $2 \mathrm{~h}$, followed by membrane washing. Then, electrochemical luminescence (ECL) scotography was performed. A gel imager was used for scanning or photographing. Gray value was measured using Gel Pro 4.0 image analysis software (Media Cybernetics, Inc., Rockville, MD, USA).

Role of silenced mdig in proliferation of NCI-H1650 cells disclosed through 3-(4,5)-dimethylthiazol (-z-y1)-3,5-diphenyl tetrazolium bromide (MTT) assay. A single cell suspension was inoculated into a 96 -well plate, with $5 \times 10^{3}$ cells in each well. Then, siRNA experiment was performed. After $48 \mathrm{~h}, 20 \mu \mathrm{l}(5 \mu \mathrm{g} / \mu \mathrm{l}) \mathrm{MTT}$ solution was added into each well and the plate was incubated for $4 \mathrm{~h}$ in the dark. After that, $100 \mu$ dimethyl sulfoxide (DMSO) solution was added to each well and the plate was vibrated to dissolve purple crystals. A microplate reader (Thermo Fisher Scientific, Waltham, MA, USA) was applied to measure absorbance [optical density (OD) value] at $490 \mathrm{~nm}$, and the cell proliferation rate was calculated as: proliferation rate $=(\mathrm{OD}$ in mdig siRNA group $/$ OD in control group) $\mathrm{x} 100 \%$.

Influence of silenced mdig on NCI-H1650 cell cycle discovered via flow cytometry. Cells transfected for $48 \mathrm{~h}$ were collected from each group and fixed overnight at $4^{\circ} \mathrm{C}$ in pre-cooled $70 \%$ ethanol. The cells were re-suspended in $500 \mu \mathrm{l}$ staining buffer, added with $25 \mu \mathrm{l}$ propidium iodide (PI) $(50 \mu \mathrm{g} / \mathrm{ml})$ and $10 \mu \mathrm{l}$ ribonuclease A (RNase A) $(10 \mathrm{mg} / \mathrm{ml})$, mixed evenly and incubated at $37^{\circ} \mathrm{C}$ for $30 \mathrm{~min}$. Subsequently 
Table III. Effect of mdig siRNA on cell cycle of NCI-H1650 cells.

\begin{tabular}{llcc}
\hline & \multicolumn{2}{c}{ Proportion of cells in different phases (\%) } \\
\cline { 2 - 4 } Group & G1 phase & S phase & G2/M phase \\
\hline Control & $64.53 \pm 3.24$ & $24.20 \pm 3.31$ & $11.27 \pm 2.17$ \\
N-siRNA & $66.38 \pm 2.95$ & $22.07 \pm 3.52$ & $11.55 \pm 1.98$ \\
mdig siRNA & $81.45 \pm 4.33^{\mathrm{a}}$ & $9.66 \pm 1.93^{\mathrm{a}}$ & $8.89 \pm 1.13$ \\
\hline
\end{tabular}

In comparison with control group, ${ }^{\mathrm{a}} \mathrm{p}<0.01$.

the cells were washed with phosphate-buffered saline once. Cell cycle analysis was performed using a flow cytometer (Becton Dickinson and Company, Franklin Lakes, NJ, USA), and the proportion of cells in different phases was expressed as a percentage $(\%)$.

Effect of silenced mdig on NCI-H1650 cell apoptosis through flow cytometry and western blot analysis. Cells were collected from each group after $48 \mathrm{~h}$ of transfection, and then added with $0.3 \mathrm{ml}$ binding buffer suspension cells. Each test sample was added with $5 \mu$ l Annexin V and $5 \mu \mathrm{l}$ PI, incubated in the dark at room temperature for $15 \mathrm{~min}$, and added with additional $0.2 \mathrm{ml}$ binding buffer. A flow cytometer (Becton Dickinson and Company) was used to detect the apoptotic rate of cells in each group.

Cells were transfected for $48 \mathrm{~h}$ and then collected. Expression of cleaved caspase-3 and cleaved PARP1 proteins in cells in each group was detected as described earlier.

Statistical analysis. Statistical Product and Service Solutions (SPSS) 17.0 software (International Business Machines Corporation, Armonk, NY, USA) was used for data analysis. Data are expressed as mean \pm standard deviation (SD). The $\mathrm{t}$-test was employed for comparison among groups. $\mathrm{P}<0.05$ suggested that the difference was statistically significant.

\section{Results}

Impact of mdig siRNA on mRNA expression of mdig in NCI-H1650 cells. After transfection for $48 \mathrm{~h}$, the expression level of mdig mRNA in the mdig siRNA group was significantly lower than that in control group $(\mathrm{p}<0.01)$ (Fig. 1). However, there was no significant difference in the expression level of mdig mRNA between control group and N-siRNA group, suggesting that mdig siRNA can specifically interfere with the expression of mdig mRNA.

Effect of mdig siRNA on protein expression of mdig in NCI-H1650 cells. After $48 \mathrm{~h}$ of transfection, changes in mdig protein level were detected through western blotting. The results revealed that compared with that in control group, expression level of mdig protein in cells in mdig siRNA group was distinctly decreased $(\mathrm{p}<0.01)$ (Fig. 2). Changes in the expression levels of mdig protein in both control group and $\mathrm{N}$-siRNA group were not significant, indicating that mdig

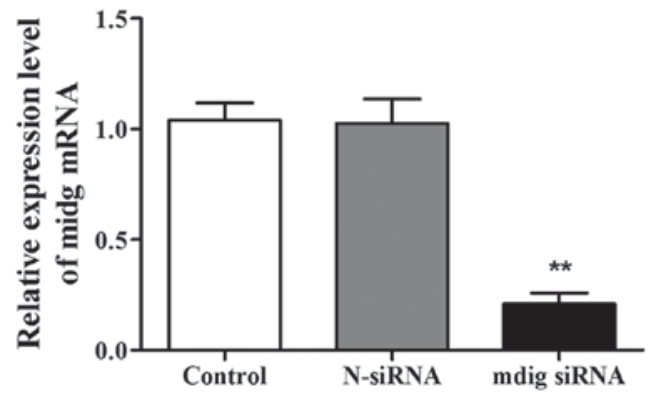

Figure 1. Expression of mdig mRNA in NCI-H1650 cells detected via RT-qPCR. In comparison with control group, the mdig siRNA group has an obviously reduced expression of mdig mRNA in NCI-H1650 cells, ${ }^{* *} \mathrm{p}<0.01$.
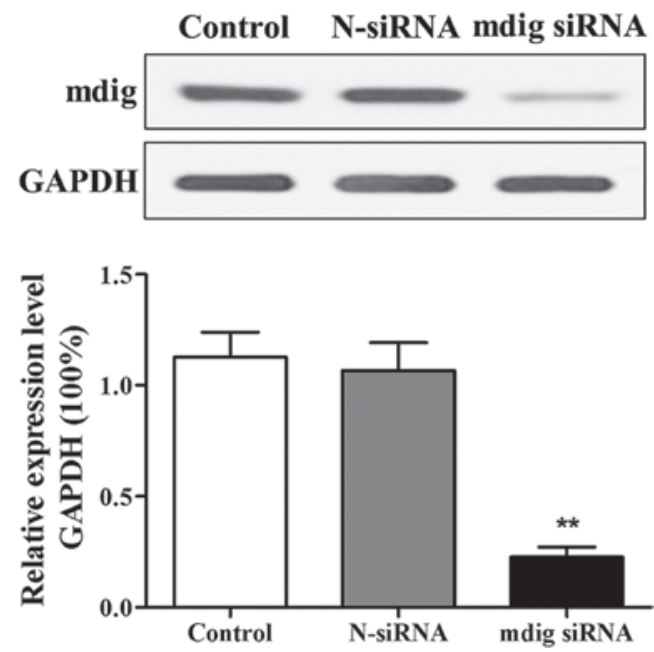

Figure 2. Expression of mdig protein in NCI-H1650 cells detected by western blot analysis. Expression level of mdig protein in NCI-H1650 cells is clearly decreased in mdig siRNA group vs. the control group, ${ }^{* *} \mathrm{p}<0.01$.

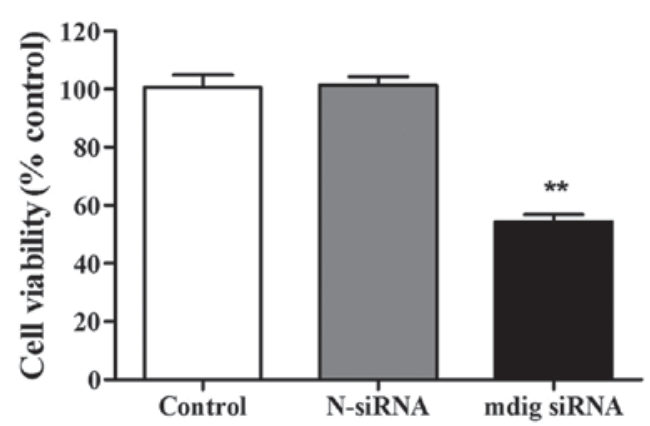

Figure 3. Viability of NCI-H1650 cells detected by MTT assay. Viability of NCI-H1650 cells in mdig siRNA group is overtly lower than that in control group, ${ }^{* *} \mathrm{p}<0.01$.

siRNA is able to specifically interfere with expression of mdig protein.

Role of mdig siRNA in of NCI-H1650 cell proliferation. The role of mdig siRNA in the proliferation ability of NCI-H1650 cells was detected through MTT assay. There was no evident difference in cell viability between control group and $\mathrm{N}$-siRNA group. Cell viability was obviously inhibited in mdig siRNA group compared to control group ( $\mathrm{p}<0.01)$ (Fig. 3). 

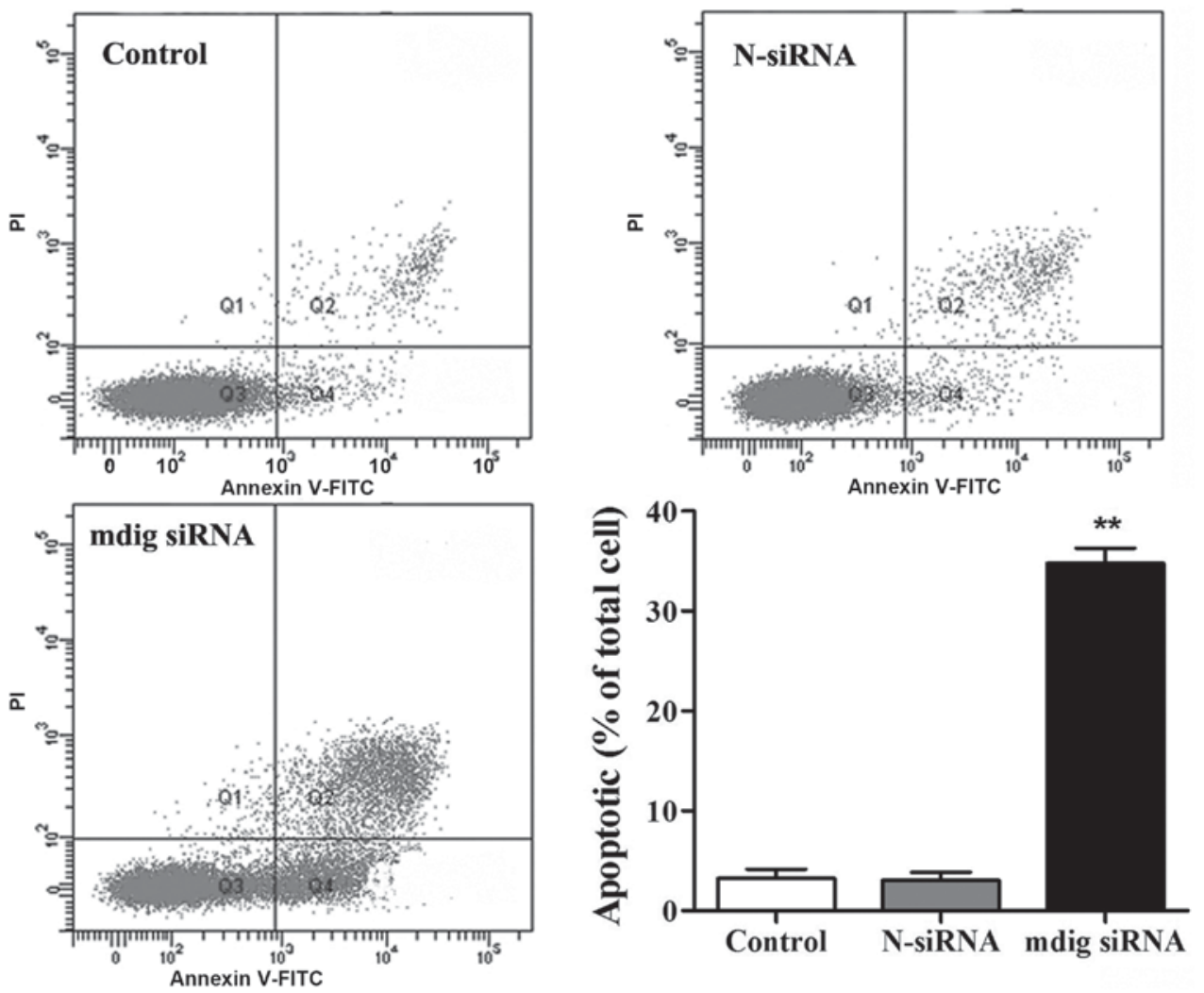

Figure 4. Detection of NCI-H1650 cell apoptosis via Annexin V-FITC flow cytometry. In comparison with control group, mdig siRNA group has a distinctly upward proportion of apoptotic cells, ${ }^{* *} \mathrm{p}<0.01$.
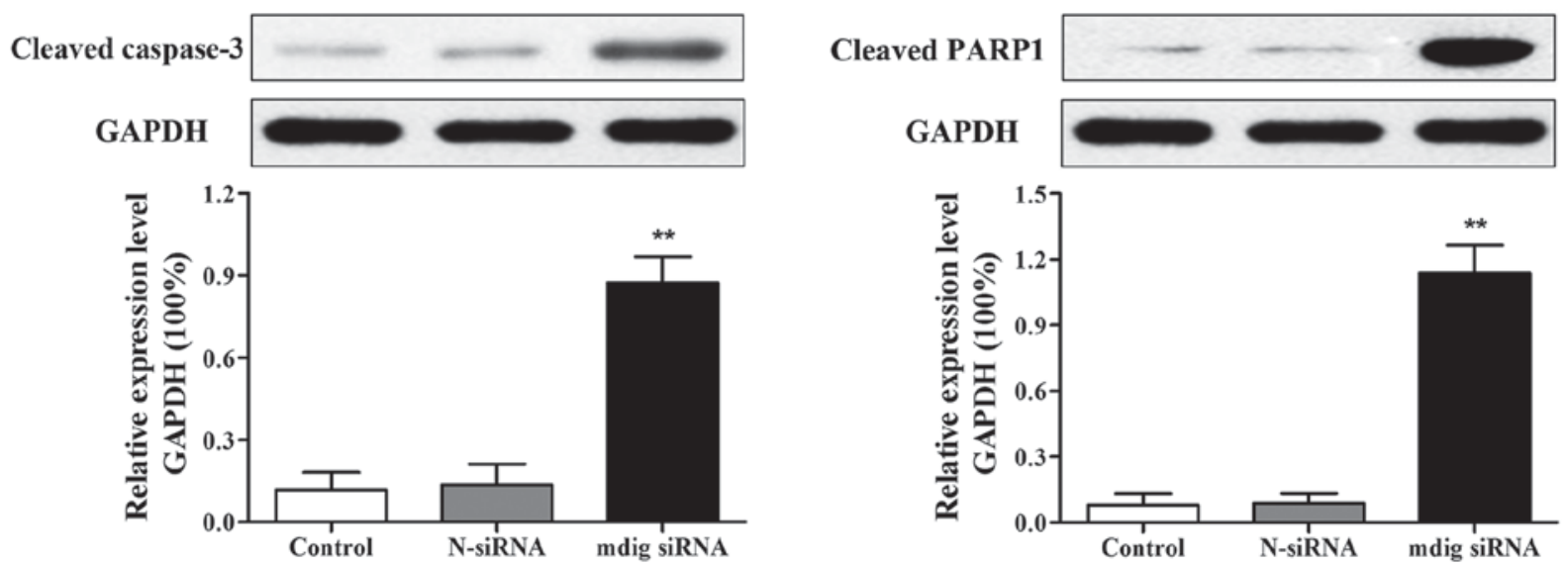

Figure 5. Measurement of expression of cleaved caspase-3 and cleaved PARP1 in NCI-H1650 cells using western blot analysis. Expression levels of proteins (cleaved caspase-3 and cleaved PARP1) in mdig siRNA group is significantly enhanced compared with those in control group, ${ }^{* *} \mathrm{p}<0.01$.

Effect of mdig siRNA on cell cycle of NCI-H1650 cells. Effect of mdig siRNA on cell cycle of NCI-H1650 cells was observed via flow cytometry. Compared to control group, the mdig siRNA group had significantly increased proportion of cells in G1 phase $(\mathrm{p}<0.01)$, and clearly decreased proportion of cells in $S$ phase $(p<0.01)$ (Table III). However, in G2 phase there were no obvious changes: proportion of cells in different phases was not changed evidently in either the control group or N-siRNA.

Influence of mdig siRNA on of NCI-H1650 cell apoptosis. Annexin V-FITC apoptosis detection kits were used for the detection of impact of mdig siRNA on apoptosis of NCI-H1650 cells. No obvious difference was found in apoptosis between the control and N-siRNA groups (Fig. 4). Compared to that in control group, the proportion of apoptotic cells in mdig siRNA group was overtly increased $(\mathrm{p}<0.01)$.

Effects of mdig siRNA on the expression of apoptotic proteins in NCI-H1650 cells. After transfection for $48 \mathrm{~h}$, the expression of apoptotic proteins (cleaved caspase-3 and cleaved PARP1) was measured via western blot analysis, and the results revealed that expression levels of cleaved caspase-3 and cleaved PARP1 were obviously increased in mdig siRNA group than those in control group $(\mathrm{p}<0.01)$. No visible changes in expression levels 
of cleaved caspase-3 and cleaved PARP1 were observed in control group or N-siRNA group (Fig. 5).

\section{Discussion}

Lung cancer is a malignancy with the highest morbidity and mortality worldwide $(17,18)$. Research data have shown that the incidence of lung cancer is on the increase in China, and China may become the Top 1 in lung cancer morbidity and mortality worldwide if no effective preventive and control measures are taken (19). At present, deaths caused by lung cancer are more than that due to liver cancer and account for approximately $23 \%$ of the total deaths caused by malignancies making lung cancer the leading cause of death caused by malignant tumors (20). Therefore, lung cancer seriously affects life and health, and new breakthroughs in its clinical treatments and drugs must be made.

The mdig-encoded protein has a molecular weight of $53 \mathrm{kDa}$, and is mainly located in the nucleus. The protein contains a conserved Jumonji C (JmjC) domain that determines the function of mdig protein (21). A study found that mdig is highly expressed in lung cancer, esophageal cancer, gastric cancer and other tumors, and that mdig is a protooncogene (22). A study by Zhang et al revealed that mdig is a mineral dust-induced gene, and that the expression level of mdig mRNA is significantly enhanced when NCI-H1650 cells are treated with silica (23). In addition, it was found in the study by Komiya et al that mdig is a target gene of protooncogene c-myc that can induce overexpression of mdig (24). A study by Lu et al revealed that various lung cancer cell lines have high mdig expression, and in patients with lung cancer, expression of mdig mRNA is increased by more than 6 times in lung cancer tissues than that in normal tumor-adjacent tissues (25). Caspase-3 plays a key role in the process of apoptosis; when caspase- 3 is cleaved and activated, cells enter an irreversible process of apoptosis (26). PARP1 is a kind of DNA repair enzyme in the nucleus, while cleaved caspase-3 can cleave and activate PARP1, leading to unrepaired cell DNA damage, thereby resulting in apoptosis (27).

In this study, mdig siRNA was used to transfect NCI-H1650 cells and silence mdig expression in the cell line. RT-qPCR and western blot analysis were used to detect mRNA and protein expression of mdig in NCI-H1650 cells. The results showed that mdig siRNA was able to significantly decrease expression of mRNA and protein of mdig in NCI-H1650 cells and the roles of mdig in proliferation, cell cycle and apoptosis of NCI-H1650 cells. Furthermore, we found that silenced mdig clearly reduced proliferation capabilities of NCI-H1650 cells and blocked NCI-H1650 cells in G1 phase. At the same time, this study employed flow cytometry and western blotting to observe the impact of silenced mdig on apoptosis of NCI-H1650 cells, and the results revealed that the apoptotic rate of NCI-H1650 cells in mdig siRNA group was obviously increased. Western blot analysis, revealed that, silenced mdig upregulated the expression of cleaved caspase- 3 and cleaved PARP1 proteins in NCI-H1650 cells, thereby inducing apoptosis. It was found that in pancreatic cancer PANC-1 cells, apoptosis rate of cells was overtly enhanced when PANC-1 cells were transfected with mdig siRNA, suggesting that mdig is capable of inhibiting apoptosis in PANC-1 cells (28).
In conclusion, mdig has a high expression in lung cancer NCI-H1650 cells. In addition, mdig siRNA is able to inhibit proliferation and promote apoptosis of NCI-H1650 cells. The underlying mechanism may be linked to inhibited cell cycle progression and upward expression of apoptosis proteins (cleaved caspase-3 and cleaved PARP1).

\section{Acknowledgements}

Not applicable.

\section{Funding}

No funding was received.

\section{Availability of data and materials}

The datasets used and/or analyzed during the current study are available from the corresponding author on reasonable request.

\section{Authors' contributions}

$\mathrm{XX}$ and $\mathrm{HL}$ were responsible for PCR and western blot analysis. LC and YZ helped with cell culture and siRNA transfection. HL, ZS and YC contributed to MTT assay and flow cytometry. All authors read and approved the final manuscript.

\section{Ethics approval and consent to participate}

The study was approved by the Ethics Committee of Peking Union Medical College Hospital (Beijing, China).

\section{Patient consent for publication}

Not applicable.

\section{Competing interests}

The authors declare that they have no competing interests.

\section{References}

1. Ferlay J, Shin HR, Bray F, Forman D, Mathers C and Parkin DM: Estimates of worldwide burden of cancer in 2008: GLOBOCAN 2008. Int J Cancer 127: 2893-2917, 2010.

2. Arbyn M, Castellsagué X, de Sanjosé S, Bruni L, Saraiya M, Bray F and Ferlay J: Worldwide burden of cervical cancer in 2008. Ann Oncol 22: 2675-2686, 2011.

3. Marx A, Chan JK, Coindre JM, Detterbeck F, Girard N, Harris NL, Jaffe ES, Kurrer MO, Marom EM, Moreira AL, et al: The 2015 World Health Organization Classification of Tumors of the Thymus: Continuity and Changes. J Thorac Oncol 10: 1383-1395, 2015.

4. Jemal A, Tiwari RC, Murray T, Ghafoor A, Samuels A, Ward E, Feuer EJ and Thun MJ; American Cancer Society: Cancer statistics, 2004. CA Cancer J Clin 54: 8-29, 2004.

5. Brahmer J, Reckamp KL, Baas P, Crinò L, Eberhardt WE, Poddubskaya E, Antonia S, Pluzanski A, Vokes EE, Holgado E, et al: Nivolumab versus docetaxel in advanced squamous-cell non-small-cell lung cancer. N Engl J Med 373: 123-135, 2015.

6. Garon EB, Rizvi NA, Hui R, Leighl N, Balmanoukian AS, Eder JP, Patnaik A, Aggarwal C, Gubens M, Horn L, et al; KEYNOTE-001 Investigators: Pembrolizumab for the treatment of non-small-cell lung cancer. N Engl J Med 372: 2018-2028, 2015. 
7. Carrizosa DR and Gold KA: New strategies in immunotherapy for non-small cell lung cancer. Transl Lung Cancer Res 4: 553-559, 2015.

8. Mamdani H, Induru R and Jalal SI: Novel therapies in small cell lung cancer. Transl Lung Cancer Res 4: 533-544, 2015.

9. Zhang Y, Lu Y, Yuan BZ, Castranova V, Shi X, Stauffer JL, Demers LM and Chen F: The Human mineral dust-induced gene, mdig, is a cell growth regulating gene associated with lung cancer. Oncogene 24: 4873-4882, 2005.

10. Tsuneoka M, Koda Y, Soejima M, Teye K and Kimura H: A novel myc target gene, mina53, that is involved in cell proliferation. J Biol Chem 277: 35450-35459, 2002.

11. Ogasawara S, Komuta M, Nakashima O, Akiba J, Tsuneoka M and Yano $\mathrm{H}$ : Accelerated expression of a Myc target gene Mina53 in aggressive hepatocellular carcinoma. Hepatol Res 40: 330-336, 2010

12. Tsuneoka M, Fujita $H$, Arima $N$, Teye $K$, Okamura T, Inutsuka $H$, Koda Y, Shirouzu K and Kimura H: Mina53 as a potential prognostic factor for esophageal squamous cell carcinoma. Clin Cancer Res 10: 7347-7356, 2004.

13. Zhang Q, Hu CM, Yuan YS, $\mathrm{He} \mathrm{CH}$, Zhao Q and Liu NZ: Expression of Mina53 and its significance in gastric carcinoma. Int J Biol Markers 23: 83-88, 2008.

14. Ishizaki H, Yano $\mathrm{H}$, Tsuneoka M, Ogasawara S, Akiba J, Nishida N, Kojiro S, Fukahori S, Moriya F, Matsuoka K, et al: Overexpression of the myc target gene Mina53 in advanced renal cell carcinoma. Pathol Int 57: 672-680, 2007.

15. Teye K, Arima N, Nakamura Y, Sakamoto K, Sueoka E, Kimura $\mathrm{H}$ and Tsuneoka M: Expression of Myc target gene mina53 in subtypes of human lymphoma. Oncol Rep 18: 841-848, 2007.

16. Livak KJ and Schmittgen TD: Analysis of relative gene expression data using real-time quantitative PCR and the 2(-Delta Delta C(T)) Method. Methods 25: 402-408, 2001.

17. Mujica EV, Leiva ME, Rojas ME, Díaz N, Lcaza G and Palomo GI: Discordance between nutritional status and self perception of weight among adults from Talca, Chile. Rev Med Chil 137: 76-82, 2009 (In Spanish).

18. Tseng TS, Park JY, Zabaleta J, Moody-Thomas S, Sothern MS, Chen T, Evans DE and Lin HY: Role of nicotine dependence on the relationship between variants in the nicotinic receptor genes and risk of lung adenocarcinoma. PLoS One 9: e107268, 2014.
19. Taylor RC, Cullen SP and Martin SJ: Apoptosis: Controlled demolition at the cellular level. Nat Rev Mol Cell Biol 9: 231-241, 2008.

20. Wyllie AH, Kerr JFR and Currie AR: Cell death: The significance of apoptosis. Int Rev Cytol 68: 251-306, 1980.

21. Zhou J, Qian C, Zhao M, Yu X, Kang Y, Ma X, Ai Y, Xu Y, Liu D, An Y, et al; China Critical Care Clinical Trials Group: Epidemiology and outcome of severe sepsis and septic shock in intensive care units in mainland China. PLoS One 9: e107181, 2014.

22. Cakir E, Demirag E, Aydin M and Unsal E: Clinicopathologic features and prognostic significance of lung tumours with mixed histologic patterns. Acta Chir Belg 109: 489-493, 2009.

23. Zhang Y, Lu Y, Yuan BZ, Castranova V, Shi X, Stauffer JL, Demers LM and Chen F: The Human mineral dust-induced gene, mdig, is a cell growth regulating gene associated with lung cancer. Oncogene 24: 4873-4882, 2005.

24. Komiya K, Sueoka-Aragane N, Sato A, Hisatomi T, Sakuragi T, Mitsuoka M, Sato T, Hayashi S, Izumi H, Tsuneoka M, et al: Mina53, a novel c-Myc target gene, is frequently expressed in lung cancers and exerts oncogenic property in NIH/3T3 cells. J Cancer Res Clin Oncol 136: 465-473, 2010.

25. Lu Y, Chang Q, Zhang Y, Beezhold K, Rojanasakul Y, Zhao H, Castranova V, Shi X and Chen F: Lung cancer-associated JmjC domain protein mdig suppresses formation of tri-methyl lysine 9 of histone H3. Cell Cycle 8: 2101-2109, 2009.

26. Li Z, Jo J, Jia JM, Lo SC, Whitcomb DJ, Jiao S, Cho K and Sheng M: Caspase-3 activation via mitochondria is required for long-term depression and AMPA receptor internalization. Cell 141: 859-871, 2010.

27. Boulares AH, Zoltoski AJ, Yakovlev A, Xu M and Smulson ME: Roles of DNA fragmentation factor and poly(ADP-ribose) polymerase in an amplification phase of tumor necrosis factorinduced apoptosis. J Biol Chem 276: 38185-38192, 2001.

28. Andrade F, Casciola-Rosen LA and Rosen A: Granzyme B-induced cell death. Acta Haematol 111: 28-41, 2004.

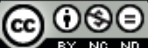

This work is licensed under a Creative Commons Attribution-NonCommercial-NoDerivatives $\quad 4.0$ International (CC BY-NC-ND 4.0) License. 